Rejane Spitz *

\title{
0 virtual como meio de transformação crítica do real
}

Rejane Spitz é Professora Associada e Coordenadora do Laboratório de Arte Eletrônica do Departamento de Artes e Design da PUC-Rio. Graduada em Desenho Industrial e em Comunicação Visual pela PUC-Rio (1979), pós-graduada em Advanced Typographic Design pela London College of Printing (Inglaterra, 1982), Mestre em Graphic Design pela Central School of Art \& Design (Inglaterra, 1983), Doutora em Educação pela PUC-Rio (1993), com pós-doutorado em Arte Eletrônica pela University of California - Berkeley (EUA, 2002) e pelo CADRE Laboratory for New Media/ San Jose State University, California (EUA, 2003). <rejane@puc-rio.br> ORCID: 0000-0002-9837-3387
Resumo Tomando por base a noção de virtual como meio de transformação crítica do real, neste artigo discutimos conceitos relacionados à imersividade, abordando aspectos de interatividade, sensação de presença, colaboração, motivação, emoção e engajamento. A partir da análise de um conjunto de obras de imersão originais e visionárias, discutimos a contribuição da Arte ao campo da Realidade Virtual. O Laboratório de Arte Eletrônica (PUC-Rio), sua metodologia de trabalho, resultados e contribuição acadêmica são descritos, e, em seguida, apresentamos nosso novo projeto "VRestaurant: alimento para o pensamento", uma instalação artística imersiva, sinestésica, gastronômica e colaborativa, cujo objetivo é discutir os desafios que enfrentamos hoje em relação à produção e ao consumo de alimentos, em escala global. Seremos capazes de alimentar 10 bilhões de pessoas no planeta, de forma saudável e sustentável, em 2050? Em conclusão, tecemos considerações sobre o papel da Arte Eletrônica em projetos que promovem conscientização, engajamento e mudanças sociais.

Palavras chave Arte Eletrônica, Realidade Virtual, Imersão, Sistemas Alimentares Sustentáveis. 


\title{
The virtual as a means of critical transformation of the real
}

\begin{abstract}
Based on the notion of the virtual as a means of critical transformation of the real, in this article we discuss concepts related to immersiveness, addressing aspects of sense of presence, interactivity, collaboration, motivation, emotion and engagement. From the analysis of a set of original and visionary immersion works, we discuss the contribution of Art to the field of Virtual Reality. The Electronic Art Laboratory (PUC-Rio), its work methodology, results and academic contribution are described. Then, we present the project "VRestaurant: food for thought", an immersive, synesthetic, gastronomic and collaborative artistic installation, whose objective is to discuss the challenges we face today in relation to the production and consumption of food, on a global scale. Will we be able to feed 10 billion people on the planet in a healthy and sustainable way by 2050? In conclusion, we make considerations about the role of Electronic Art in projects that promote awareness, engagement and social changes.
\end{abstract}

Keywords Electronic Art, Virtual Reality, Immersion, Sustainable Food Systems.

\section{Lo virtual como medio de transformación crítica de lo real}

Resumen Partiendo de la noción de lo virtual como medio de transformación crítica de lo real, en este artículo discutimos conceptos relacionados con la inmersión, abordando aspectos de sentido de presencia, interactividad, colaboración, motivación, emoción y compromiso. A partir del análisis de un conjunto de obras de inmersión originales y visionarias, se discute la contribución del Arte al campo de la Realidad Virtual. Se describe el Laboratorio de Arte Electrónico (PUC-Rio), su metodología de trabajo, resultados y aporte académico. A continuación, presentamos el proyecto "VRestaurant: alimento para el pensamiento", una instalación artística inmersiva, sinestésica, gastronómica y colaborativa, cuyo objetivo es discutir los desafíos que enfrentamos hoy en día en relación a la producción y consumo de alimentos, a escala global. ¿Seremos capaces de alimentar a 10 mil millones de personas en el planeta de una manera saludable y sostenible para 2050? En conclusión, hacemos consideraciones sobre el papel del Arte Electrónico en proyectos que promueven la conciencia, el compromiso y los cambios sociales.

Palabras clave Arte Electrónico, Realidad Virtual, Inmersión, Sistemas Alimentarios Sostenibles. 


\title{
Introdução: o poder da imersão
}

\author{
Lembre-se de como é estar imerso na água; deitar-se lentamente na ba- \\ nheira e colocar a cabeça debaixo d'água. A sensação silenciosa de estar \\ submerso em outro meio, onde as regras mudam, porque, se você respi- \\ rasse normalmente, seus pulmões se encheriam de água; então você tem \\ que prender a respiração, sentindo seu corpo flutuar neste novo reino, \\ prestando atenção a cada momento do que esta nova experiência oferece. \\ Sendo capaz, ao mesmo tempo, de relaxar diante desse sentimento sobre- \\ natural, mas mantendo-se sempre alerta, pronto a responder à eventual \\ necessidade de oxigênio de seu corpo. (MACHON, 2013, xvi)
}

No prefácio de seu livro sobre teatro imersivo, MACHON (2013) nos convida a evocar memórias de nossos primeiros mergulhos no mar, como uma maneira de entendermos melhor como a imersão é capaz de produzir intensas reações emocionais em seres humanos. De fato, a sensação de estarmos imersos num ambiente desconhecido e estranho pode se constituir numa experiência agradável e excitante para uns, e pode representar uma experiência amedrontadora e difícil, para outros. Em ambos os casos, no entanto, a imersão é, invariavelmente, uma sensação forte e impactante.

A sensação de imersão pode ser também ilusória - criada artificialmente por um conjunto de recursos e processos que atuam de forma a modificar a percepção do participante, dando-lhe a sensação de uma vivência em outro espaço, diferente do ambiente real no qual se encontra.

Ao longo da história, a imersão ilusória tem sido explorada para proporcionar sensações variadas, em geral com objetivos artísticos, místicos, religiosos ou políticos. Recursos de ilustração e pintura foram empregados, desde a Antiguidade, para criar efeitos ilusórios de imersão - como os famosos afrescos da Villa dei Misteri, em Pompéia, ou da Villa di Livia, em Roma. No século XIX, os imensos panoramas para visitação pública painéis circulares pintados, em escala natural, tendo como principais temáticas as batalhas e conquistas militares - tornaram-se muito populares na Europa, atraindo multidões de visitantes (GRAU, 2003).

Complexos projetos de simulação da realidade começaram a ser desenvolvidos no século XX, oferecendo aos participantes sensações hápticas e aromáticas, em complemento às visuais e auditivas.

Destaca-se, dentre esses pioneiros experimentos, o projeto Sensorama, uma cabine projetada pelo cineasta Morton Heilig, nos anos 50, que oferecia experiências multissensoriais. $\mathrm{O}$ projeto - um dispositivo mecânico, desenvolvido antes do surgimento da computação digital - foi descrito pelo autor como um teatro experimental que poderia abranger todos os sentidos, de forma a atrair a atenção do espectador para a atividade exibida na tela. O protótipo, finalizado em 1962, continha 5 curta-metragens para exibição, explorando, em paralelo, os sentidos de visão, audição, olfato e tato, através 
de imagens estereoscópicas coloridas (gravadas com uma câmera customizada que o próprio Heilig desenvolveu), visão periférica, aromas, movimentos, e até mesmo a simulação de vento ${ }^{1}$. Outro projeto visionário de Heilig foi o Telesphere Mask (criado em 1957 e patenteado em 1960), descrito como "um aparelho de televisão telescópico para uso individual" (BROCKWELL, 2016). Nos desenhos apresentados para obtenção de sua patente, a Telesphere Mask em muito se assemelha aos primeiros headsets de Realidade Virtual comercializados (BROCKWELL, 2016).

A literatura científica credita à Ivan Sutherland a criação do primeiro equipamento de Realidade Virtual, em 1968 - um capacete com rastreamento mecânico, apelidado como "Espada de Dâmocles", em função de sua aparência - com o qual era possível ver objetos que outras pessoas, na mesma sala, não conseguiam enxergar. Na histórica demonstração do projeto, um cubo - feito em computação gráfica - aparece superposto às imagens do mundo real (SUTHERLAND, 1968).

Com seus projetos - que incluíram ainda o famoso editor gráfico Sketchpad - e suas ideias visionárias a respeito da computação, Ivan Sutherland inaugura a era da imersão em Realidade Virtual. No parágrafo final do seu famoso artigo The Ultimate Display, publicado em 1965, ele descreve - de forma surpreendente - sua visão acerca do que seria o "monitor final", um computador capaz de controlar a existência da matéria:

\footnotetext{
O "monitor final" seria, claro, uma sala dentro da qual o computador pode controlar a existência da matéria. Uma cadeira exibida em tal sala seria boa o suficiente para se sentar. As algemas expostas em tal sala seriam confinantes, e uma bala exibida em tal sala seria fatal. Com a programação apropriada, tal exibição poderia ser literalmente o País das Maravilhas em que Alice entrou. (SUTHERLAND, 1965, p. 507)
}

Durante as décadas seguintes, a Realidade Virtual se tornou um importante campo de pesquisas na área de Ciência da Computação. Foram desenvolvidas muitas experiências e projetos imersivos, mas os computadores não eram capazes de gerar imagens foto realistas, e os primeiros headsets eram muito pesados e complexos. Tampouco os participantes se sentiam confortáveis durante a experiência de imersão, que - por conta da precariedade dos equipamentos e das técnicas - causava-lhes náusea, dor de cabeça e enjoo. Apesar do imenso potencial da Realidade Virtual, todos esses fatores conjugados inibiram seu desenvolvimento e sua popularidade, por algumas décadas.

Foi apenas durante os anos 90 que os dispositivos de Realidade Virtual ganharam grande visibilidade junto ao público - aparecendo em filmes, narrativas, jogos, arcades e parques temáticos - e, rapidamente, povoaram nosso imaginário. A despeito das dificuldades tecnológicas, artistas eletrô- 
nicos - atuando na interseção das artes, design, ciência e tecnologia - perceberam suas possibilidades expressivas, e investiram na exploração dessa poderosa nova mídia. A promessa de imersão da Realidade Virtual ganhava, enfim, novos contornos e possibilidades.

Ela coloca o headset na minha cabeça. E, de repente, saí do prédio. Subindo uma escada, flutuo, sem peso, em um mundo azul, cheio de molduras de edifícios queimados e fragmentos das memórias da artista - um minúsculo estúdio, uma mini geladeira aqui, um laptop ali, tão reais que tento agarrá-los com a mão. Com a boca aberta, olho para cima, para baixo, atrás de mim, e as imagens acompanham minha linha de visão. Aperto os olhos na primeira vez em que atravesso uma parede, abaixo minha cabeça enquanto atravesso um telhado. Por dois minutos e meio, não sinto mais as tábuas do piso de madeira, respingadas de tinta, sob meus pés. (GOTTSCHALK, 2016, online)

$\mathrm{Na}$ década de 90, vários artistas se interessaram em explorar as possibilidades de simulação da realidade em ambientes imersivos, enxergando, na Realidade Virtual, um enorme potencial para fruição e expressão artística.

Dentre as várias incursões feitas por artistas nesse novo domínio, dois projetos artísticos em Realidade Virtual merecem menção, não apenas por seu caráter pioneiro e original, mas, principalmente, por seu grande protagonismo no que concerne à exploração de processos e técnicas artísticas de imersão em Realidade Virtual:

Placeholder (1993)

Em 1993 surgia o original projeto Placeholder, de Brenda Laurel e Rachel Strickland, que explorava a ação narrativa conjunta de pessoas situadas em três diferentes ambientes virtuais, conectados por portais, em ação simultânea. Placeholder tinha a intenção de mostrar que a Realidade Virtual poderia ser usada "não apenas para treinamento, mas para estender nossa imaginação, nos deixar brincar e encontrar prazer de novas maneiras" (LAUREL, 2016, online). O projeto foi inspirado em três lugares reais dentro e ao redor do Parque Nacional de Banff, cidade onde foi desenvolvido: uma caverna contendo uma fonte termal sulfurosa, uma cachoeira e o vale de um rio. As imagens e gravações de áudio foram feitas nesses locais por Laurel, Strickland, e o pequeno exército de codificadores e atores de teatro que vieram junto com elas, para conhecer os locais e vivenciar a natureza. Para criar a envolvente narrativa de Placeholder, contaram com a ajuda de uma trupe de teatro em Banff, conhecida por suas performances divertidas e improvisadas. Os atores não tinham praticamente conhecimento algum sobre computadores ou Realidade Virtual, e por isso se tornaram "colaboradores 
ideais" no projeto, trabalhando com os comportamentos e vocalizações dos 4 personagens arquetípicos da obra - Cobra, Peixe, Aranha e Corvo. Os participantes da experiência incorporavam características sensório-motoras desses 4 diferentes animais, e - através de recursos de distorção vocal - se comunicavam entre si, emitindo sons semelhantes aos dos animais. Com a intenção de trazer o corpo de volta ao espaço virtual, a abordagem das autoras foi a de usar o gesto natural: se você era o corvo, precisava movimentar os braços, como um pássaro, para voar no espaço. Cada personagem tinha o que chamavam de "fantasia inteligente", um conjunto de habilidades perceptivas e comandos gestuais projetados para dar a cada participante uma perspectiva da experiência sensorial de outra criatura. Ou seja, ao se aproximar do corvo, uma pessoa repentinamente se tornava o corvo; quando falavam, o faziam com a voz processada digitalmente de um corvo, e quando moviam os braços, voavam pelo vale do rio. Para Laurel, numa experiência virtual de imersão bem projetada devemos ser capazes de interagir com o mundo digital exatamente como interagimos com o mundo físico, ou seja, temos que estar totalmente livres e presentes (EVANS, 2018). O projeto deu lugar a experimentações seminais em relação a interfaces naturais, sensação de presença e representação do corpo no ambiente virtual, que, ainda hoje, são consideradas relevantes e originais.

\section{Osmose (1995)}

Em 1995 era exibido, pela primeira vez, o projeto Osmose, de Char Davies, uma experiência de Realidade Virtual imersiva na qual, através do uso de headset e de colete sensível aos movimentos de respiração, os participantes podiam flutuar por paisagens poéticas, utilizando sua própria atividade de inspiração e expiração de ar dos pulmões para se movimentar pelos ambientes. Vale mencionar que quase todos os participantes, ao saírem da experiência, relataram que sentiam-se bastante emocionados, alguns quase sem palavras - como o artista Henry See, cuja emoção foi registrada em vídeo $^{2}$. Há, também, relatos de que algumas pessoas saíram da experiência chorando copiosamente (GOTTSCHALK, 2016).

\footnotetext{
Com base nas respostas de aproximadamente 25.000 indivíduos que estiveram imersos em Osmose, desde 1995, o efeito posterior da imersão na obra pode ser bastante profundo, como se tivessem redescoberto um aspecto de si próprios que haviam esquecido, de estarem vivos no mundo, uma experiência que muitos consideram surpreendente, e alguns, muito emocionante. [...] o espaço virtual imersivo, quando despojado de suas convenções, pode fornecer um contexto espaço-temporal intrigante para se explorar a experiência subjetiva de "estar no mundo", um espaço envolvente onde as fronteiras entre o interior/exterior, e a mente/corpo se dissolvem. (http://www.immersence.com/osmose/)
} 
Ambos os projetos acima descritos foram obras artísticas visionárias e de complexa execução, que envolveram a participação de equipes interdisciplinares. Ambas apresentaram conceitos originais, desenvolveram extensa pesquisa de conteúdos, técnicas e formas, e trouxeram grande contribuição ao campo da Realidade Virtual através da pesquisa de elementos relativos à imersão, sensação de presença e navegação, efeitos sonoros e plásticos, sofisticadas tecnologias de captação de dados e interatividade.

Em especial, destaca-se o alto grau de envolvimento e engajamento que ambos os projetos alcançaram em relação à experiência vivida durante a imersão, segundo relatos e depoimentos dos próprios participantes.

A título de complemento às informações desta seção, incluo, aqui, mais alguns detalhes curiosos. Tive a oportunidade de estar presente em alguns momentos importantes da Arte Eletrônica, e de testemunhar pessoalmente alguns dos fatos descritos nos exemplos acima. Assisti, por exemplo, à Brenda Laurel em 1991, que encantou sua audiência, na conferência SIGGRAPH'91, tecendo interessantes comparações entre a computação e o teatro. Citando seu livro Computers as Theatre, publicado alguns meses antes, Laurel dizia que o teatro servia de base para um modelo de relação humano-computador amigável, intuitivo e compreensível. Decorridos 30 anos desde então, ainda me recordo de seus exemplos e estórias sobre a aplicação de técnicas de imersão como prática para a atuação dramática, e como isso se associava diretamente à noção de imersão em Realidade Virtual.

Estava, também, na plateia da conferência FISEA'93 - The Art Factor, realizada em Minneapolis (EUA), quando Brenda Laurel apresentou, animadamente, seu projeto em andamento, Placeholder, exibido pela primeira vez naquele mesmo ano. Laurel havia assistido à minha palestra (SPITZ, 1995) naquele mesmo evento, e conversamos sobre o papel da Arte Eletrônica no Brasil, seus desafios e potencialidades.

Também tive a oportunidade de vivenciar a experiência de imersão em Osmose, em 1995, pois fazia parte do comitê de organização do evento ISEA 1995, realizado em Montreal (Canadá), onde a obra estava sendo exibida. Havia um livro de anotações, à saída da instalação, onde os visitantes podiam deixar seus comentários e impressões sobre a experiência vivida. Deixei registrado um comentário sobre a forte sensação que tive de estar em trabalho de parto, e da vontade que senti, durante a experiência, de estar junto aos meus filhos. Depois, ao ler outras anotações feitas no livro, achei um outro relato praticamente igual ao meu, o que achei extremamente interessante, pois não há absolutamente nenhuma representação em Osmose que remeta diretamente à temática de parto, nascimento e família.

Mais recentemente, em 2018, estive presente na comemoração de 50 anos do Head-Mounted 3D Display System de Ivan Sutherland, na qual ele próprio - e vários de seus colaboradores - contaram divertidas estórias e apresentaram imagens históricas da Realidade Virtual. "Nunca pensei muito no futuro. Eu não conseguia imaginar o que as pessoas fariam com isso. Só fiz isso porque era interessante e parecia possível", disse Sutherland, no evento. Outro detalhe curioso revelado no Painel foi que "realidade virtu- 
al" não é o termo que o cientista teria usado para descrever sua tecnologia: "Foi Jaron Lanier quem a nomeou alguns anos depois - talvez 10. E sempre achei que era um nome um tanto estranho... O capacete HMD que construímos em Harvard não era muito real, nem envolvente." ${ }^{3}$

\section{Engajamento, presença e motivação}

Hoje contamos com o apoio de sofisticadas tecnologias computacionais para tornar mais tênue a linha de separação entre realidade e ilusão, ampliando os limites de nossa imaginação. As experiências virtuais tornam-se ainda mais imersivas à medida que o desenvolvimento tecnológico possibilita o aumento das informações sensoriais capturadas e fornecidas. A literatura científica sugere, por exemplo, que quando o usuário percebe o movimento natural de seus braços e pernas no mundo virtual, há uma maior sensação de presença (OLIVEIRA, 2019). Mas para que os participantes se sintam presentes em uma realidade alternativa, é preciso que se propicie um alto grau de engajamento. Afinal, a imersão é um estado psicológico caracterizado por "perceber-se envolvido por, incluído e interagindo com um ambiente que fornece um fluxo contínuo de estímulos e experiências." (FAUVILLE et al., 2018, p. 93)

Com a ajuda de temáticas de interesse e narrativas envolventes, recursos artísticos sinestésicos e elementos cênicos, bem como, em certos casos, por meio de ações e interferências realizadas pelos próprios participantes da experiência, pode-se criar um satisfatório nível de engajamento dos participantes, de modo a fazer com que se sintam presentes no ambiente virtual.

Tal sensação - de "estar presente" - vai ser sentida pelo participante em maior ou menor grau de intensidade, dependendo de vários fatores: das características da narrativa, dos efeitos sinestésicos criados, do ambiente simulado, do grau de interatividade propiciado e exigido, bem como das características biológicas, psicológicas e socioculturais do próprio participante.

É o sentimento subjetivo de presença, sugerem FAUVILLE et al. (2018), que faz com que alguém (que, na verdade, está fisicamente em uma grande sala vazia), quando imerso em Realidade Virtual e vivenciando uma experiência de terremoto, se ajoelhe e mergulhe sob uma mesa que existe apenas no mundo virtual. $\mathrm{O}$ terremoto não apresenta nenhum risco físico ao usuário, mas consegue desencadear essa reação de busca de proteção. Outro fator importante é a suspensão de descrença - quase um pacto firmado entre o autor e o participante para que a obra seja apreciada como se fosse verdadeira, mesmo sabendo se tratar de uma ficção - que ajuda a possibilitar esse engajamento e interação do sujeito participante, pois dessa forma irá vivenciá-la como se fosse verdadeira.

Embora a experiência narrativa em RV se assemelhe com a vivenciada num espetáculo de teatro, são raros os casos em que se pode compartilhar a experiência com outras pessoas, em tempo real. Ainda hoje, quase todas as experiências de realidade virtual são individuais, gerando uma experiência solitária, isolando o sujeito participante do restante das pessoas 
(KOETSIER, 2018). Há muitas questões que dificultam a implementação de sistemas colaborativos de RV, relacionadas, por exemplo, ao gerenciamento de recursos de rede, ao processamento gráfico em tempo real e à sincronização de visão em aplicações multiusuários, além de outras questões especificas, como a dificuldade de se manipular objetos do mundo virtual e "a necessidade de se criar avatares realistas para ampliar tanto a capacidade de comunicação entre os participantes quanto o sentimento de presença no grupo." (FILIPPO et al., 2007, p. 174).

Ainda assim, algumas experiências recentes têm explorado as possibilidades de imersão virtual conjunta - como por exemplo, o "Teatro Imersivo de Realidade Mista" (IMRT) - termo cunhado pelo NYU Future Reality Lab para definir um novo tipo de atividade performática imersiva:

\footnotetext{
Com propriedades únicas e inovadoras que não pertencem ao cinema nem ao teatro tradicional, IMRT promete novas possibilidades expressivas emocionantes para narrativas digitais imersivas, participativas, em sistema multiusuário. (GOCHFELD et al., 2018, p. 362).
}

O trabalho apresentado pelo grupo no Future of Storytelling Festival, em 2017, chamava-se Holojam in Wonderland. No ano seguinte, este mesmo grupo apresentou a instalação CAVE - um projeto para ser assistido da forma como se assiste a um show, no teatro tradicional: o publico permanece sentado, numa experiência virtual passiva, e cada espectador vivencia a mesma narrativa, mas de pontos de vista diferentes, de acordo com os locais físicos de seus assentos:

\footnotetext{
"Os efeitos combinados da história, design, som e presença compartilhada do público resultam em uma experiência coletiva semelhante a assistir a um teatro ao vivo, mas com a capacidade adicional de se criar efeitos impressionantes, muito além das limitações físicas da produção em teatro." (LAYNG et al., 2019, p. 350).
}

Além disso, nessa experiência, cada assistente na plateia é representado por um avatar, no mundo virtual. Os autores destacam que tal passividade se difere de outros projetos multiusuários em Realidade Virtual, quando as experiências são mais semelhantes a jogos onde cada usuário assume uma função ativa, respondendo e/ou alterando o conteúdo. Essa experiência também mostrou que a realidade virtual narrativa é melhor vivenciada junto com outras pessoas, pois a audiência compartilhada do publico amplifica as emoções.

O coordenador do Virtual Human Interaction Lab da Universidade de Stanford, Jeremy Bailenson, considera que agora que tais experiências estão se popularizando, em virtude dos equipamentos de Realidade Virtual serem cada vez mais accessíveis ao publico, é preciso questionar como esse novo meio afeta seus usuários, e como pode ser utilizado em novas aplicações. De fato, os poucos - mas significativos - experimentos recentes nas áreas de educação e saúde indicam seu imenso potencial de uso e aplicação 
nessas situações, demonstrando seus inúmeros benefícios e ganhos em relação aos resultados obtidos, quando comparados aos de outros métodos tradicionais. Este é o caso, por exemplo, de experimentos de Realidade Virtual feitos com pacientes hospitalizados por longos períodos, aplicação de vacinação e/ou procedimentos dolorosos e invasivos em crianças, uso em pacientes em tratamento odontológico, dentre muitos outros. Em seu livro Experience on Demand, o referido pesquisador discute em quais situações tais tecnologias se tornam mais necessárias e úteis, como, por exemplo, treinando socorristas para catástrofes naturais, como terremotos, ou permitindo que os cirurgiões pratiquem cirurgias complicadas - antes de executarem o procedimento em uma pessoa viva - ou, ainda, ajudando a aliviar a dor de vítimas de queimaduras, e de outros pacientes com dores crônicas, dentre outras situações. Um artigo publicado, este ano, pelo Virtual $\mathrm{Hu}-$ man Interaction Lab, discute como a Realidade Virtual tem sido usada com sucesso para ajudar a tratar uma variedade de condições de saúde mental. "Usar a realidade virtual para ativação comportamental pode eliminar as barreiras que as precauções pandêmicas coloca, e ajudar a diminuir os sintomas de depressão que são especialmente exacerbados nestes tempos." (PAUL et al., 2020, p. 1)

\section{Interseção, hibridismo e colaboração}

Há quase 30 anos, desde a criação do Laboratório de Arte Eletrônica (LAE) na PUC-Rio, investigamos sistematicamente o campo das Mídias Digitais. Buscamos entender suas caraterísticas e contribuições, explorar criativamente suas potencialidades, discutir seus impactos e desafios, contribuir para resolver problemas já existentes, e, ainda, prever, prospectar, criar e projetar cenários futuros, sempre atuando de modo interdisciplinar, em conjunto com outras áreas do saber.

Nossas pesquisas abarcam três eixos de investigação científica: pesquisas "dentro das Artes e Design", pesquisas "através das Artes e Design", e ainda pesquisas "para as Artes e Design" (FRAYLING, 1993, p. 5). Desenvolvemos projetos na interseção das áreas de Artes, Design, Ciência e Tecnologia, atuando de forma não-comercial, sem fins lucrativos, subsidiados por agências de fomento à pesquisa ou em parceria com instituições acadêmicas, governamentais, organizações não-governamentais ou empresas. Nossos projetos têm por meta sensibilizar, engajar e transformar o cidadão, facilitando o entendimento de questões complexas, gerando conhecimento de forma accessível, inteligível, lúdica e interativa, e permitindo a conscientização do publico em relação a temas relevantes para o ser humano e o meio ambiente.

Tratamos de temáticas sociais relevantes: na área da saúde, segurança alimentar e prevenção de doenças, desenvolvemos o projeto DYET - Do You Eat This?, voltado à conscientização sobre a ingestão excessiva de aditivos químicos em alimentos processados (SPITZ et al, 2018); fomos responsáveis pela Campanha Brasileira de Advertências Sanitárias contra o Fumo 
(NASCIMENTO et al, 2010; SPITZ e GAMBA Jr., 2007), e atuamos no projeto Sentidos do Nascer, que trata dos procedimentos relativos ao parto e ao nascimento (SPITZ et al, 2017), bem como no projeto Você Tem Fome de Que? (SPITZ, 2005), que abordou questões sobre a fome, segurança alimentar e miséria no Brasil. Trabalhamos ainda com questões de preservação do meio ambiente, como o Projeto PIMAR (SPITZ, 2010), e de popularização da ciência, como o Observatório Livre (SPITZ, 2010) e, na área da educação, investigamos inúmeras frentes de ensino de tecnologias digitais nas Artes e Design (SPITZ, 2014) e questões de analfabetismo digital (SPITZ, 2001).

Nossas equipes englobam alunos de graduação, pós-graduação e docentes de Artes, Design, Arquitetura e Informática, contando sempre, também, com a colaboração de ex-alunos - que, em geral, já fizeram parte de nossa equipe anteriormente, e voltam ao LAE - então como profissionais - para atuar em projetos específicos. Todos os membros da equipe participam de todas as fases dos projetos. "Não há saber mais ou saber menos, mas saberes diferentes" (FREIRE, 1987, p. 68).

A necessidade da interseção de conhecimentos e práticas oriundos das ciências humanas, sociais e exatas tem nos exigido um esforço especial, no sentido de buscarmos parcerias e colaborações. Contamos, atualmente, com o apoio de instituições de pesquisa e ensino brasileiras, como o MediaLab da Universidade Federal Fluminense, Instituto Tecgraf de Desenvolvimento de Software Técnico-Científico da PUC- Rio (TecGraf) e parcerias internacionais com o Departamento de Design da Universiity of Leeds (no Reino Unido), a LEONARDO (International Society for the Arts, Science and Technology) e ACM SIGGRAPH Education Committee. Essas parcerias nos permitem atualizar conhecimentos, trocar experiências, utilizar técnicas e equipamentos computacionais muitas vezes inexistentes ou inaccessíveis para o campo das Artes \& Design, e formar equipes multidisciplinares.

\section{VRestaurant: alimento para o pensamento}

A produção global de alimentos ameaça a estabilidade climática e a resiliência dos ecossistemas, causando acelerada degradação ambiental do planeta. Dietas alimentares insalubres - tanto as que acarretam desnutrição, quanto as que levam à obesidade - são outra fonte de preocupação quanto ao futuro.

Enquanto mais de 800 milhões de pessoas (ou seja, mais de 1 em cada 10 pessoas do planeta) sofrem de desnutrição, os níveis de sobrepeso e obesidade da população global continuam a aumentar, afetando mais de 2 bilhões de crianças e adultos, que apresentam distúrbios alimentares, doenças e condições crônicas. Outro dado impressionante refere-se à imensa quantidade de alimentos perdidos ou desperdiçados no percurso do campo ao consumo, em razão de fatores diversos, tais como problemas no acondicionamento, questões de transporte, má conservação, falhas na refrigeração, ou até mesmo o consumo excessivo desnecessário. Segundo a Organização das Nações Unidas para Alimentação e Agricultura (FAO), um terço 
dos alimentos produzidos anualmente para o consumo humano se perde ou é desperdiçado, o que equivale à cerca de 1.300 bilhões toneladas de alimentos, que seriam suficientes para alimentar 2 bilhões de pessoas (REGALADO, 2020). O Brasil está na lista dos dez países que mais desperdiçam alimentos no mundo, gerando descarte de aproximadamente $30 \%$ de tudo que é produzido para o consumo.

Seremos capazes de alimentar 10 bilhões de pes-

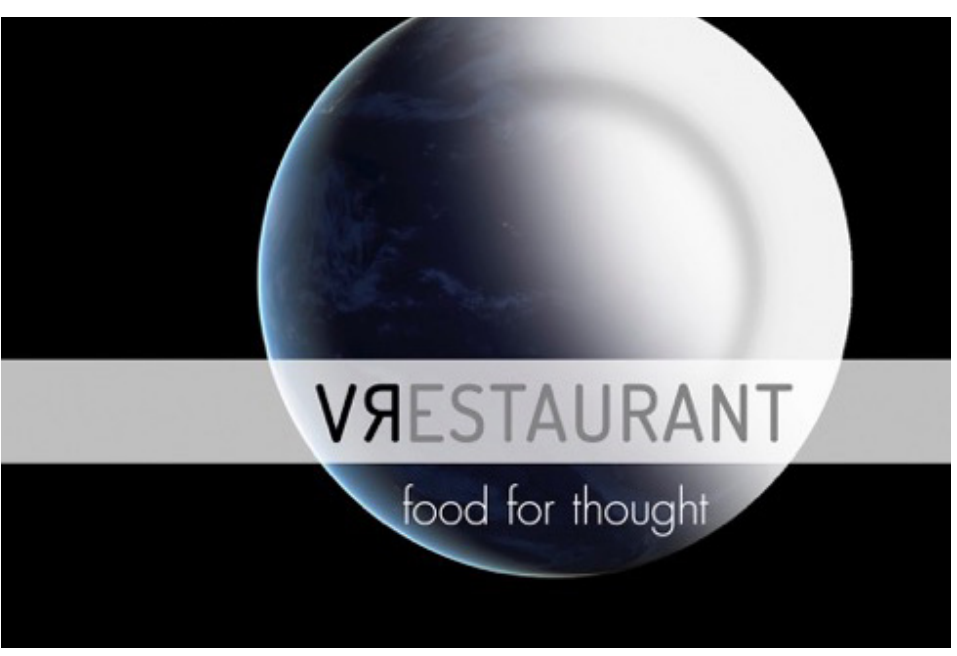

Fig 1. Logo do Projeto VRestaurant

Fonte: Projeto VRestaurant, LAE/PUC-

-Rio, 2021 soas com uma dieta saudável, em 2050, dentro dos limites do nosso planeta?

A instalação artística "VRestaurant: alimento para o pensamento" (Figura 1) - em desenvolvimento no Laboratório de Arte Eletrônica (PUC-Rio) - aborda os principais desafios que enfrentamos em relação à produção e ao consumo de alimentos.

De modo lúdico, sinestésico e colaborativo, imersos em Realidade Virtual (Figuras 2 e 3), os participantes dessa experiência absorvem e compartilham informações sobre o tema, enquanto saboreiam itens de um cardápio gastronômico original e aromático, criado especialmente para o projeto.

Através de uma narrativa envolvente, por meio de áudios pré-gravados e de interações ao vivo, nossa Chef informa dados, indaga questões, conecta os participantes, propõe atividades e elucida eventuais duvidas sobre alimentação.

Como os alimentos que você ingere afetam sua saúde e a saúde do planeta?
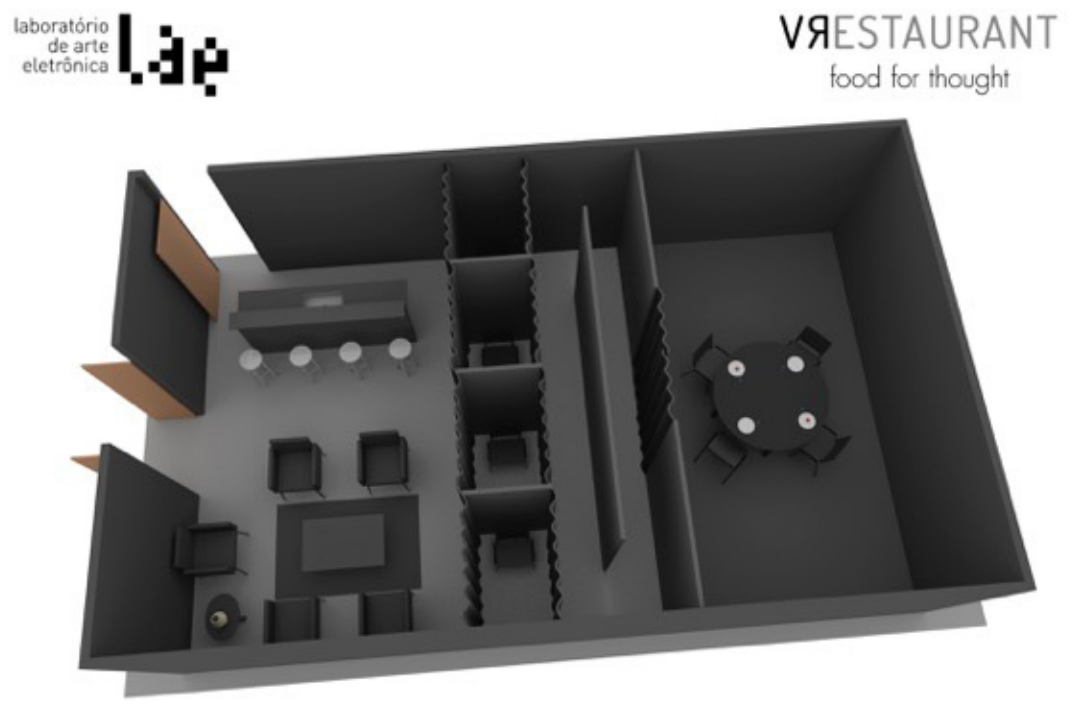

Fig 2. Layout geral da instalação Fonte: Projeto VRestaurant, LAE/PUC-Rio, 2021 
Fig 3. Exemplo de efeitos de Realidade Virtual | Fonte: Projeto VRestaurant, LAE/PUC-Rio, 2021
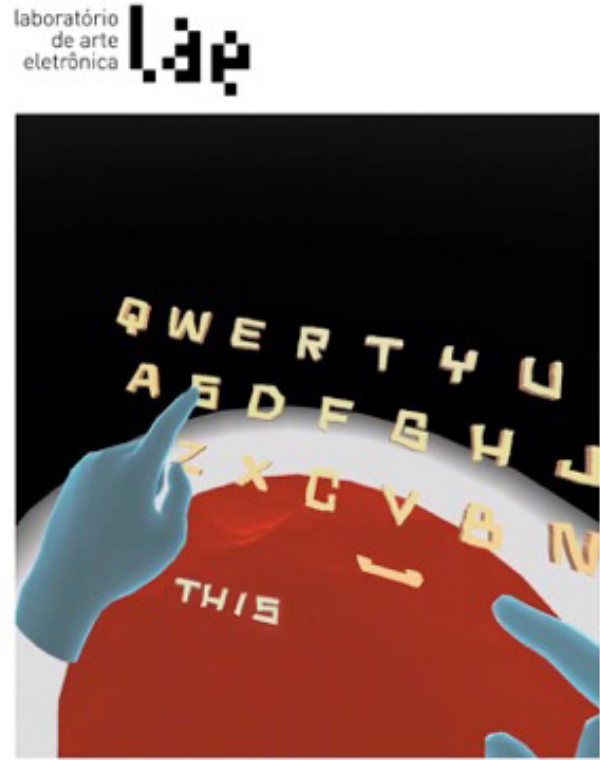

Na última década, as pessoas começaram a perceber - e a se preocupar - com o quão pouco sabem sobre as origens do que comem (GONZALEZ, 2019).

Quanto tempo levou para que esse alimento fosse transportado, até chegar à sua mesa? Onde e como o alimento foi cultivado? Quem foram as pessoas envolvidas nessa cadeia de produção, venda e transporte? Como elas vivem? Como manipulam os alimentos produzidos?

Durante a experiência imersiva - de forma criativa e lúdica, utilizando técnicas e recursos de imersão sinestésica e efeitos originais de Realidade Virtual - trataremos de vários temas relativos à produção e consumo de alimentos, tais como:

- Produção sustentável dealimentos:agrobiodiversidade e sistema agrícola

- industrial

- Desmatamento e exploração de recursos naturais

- Cadeia alimentar curta: a importância da alimentação local

- Desperdício e reaproveitamento de alimentos

- Força de trabalho e bem-estar animal

- Alimentos processados e aditivos artificiais

E discutiremos, ainda, as seguintes questões:

- Perda imensa de biodiversidade animal e vegetal, foco na quantidade em vez da qualidade, OGM, produtos químicos e pesticidas, alimentos como commodities

- Uso excessivo do solo, desmatamento, efeito estufa, emissão de gases, uso da água 

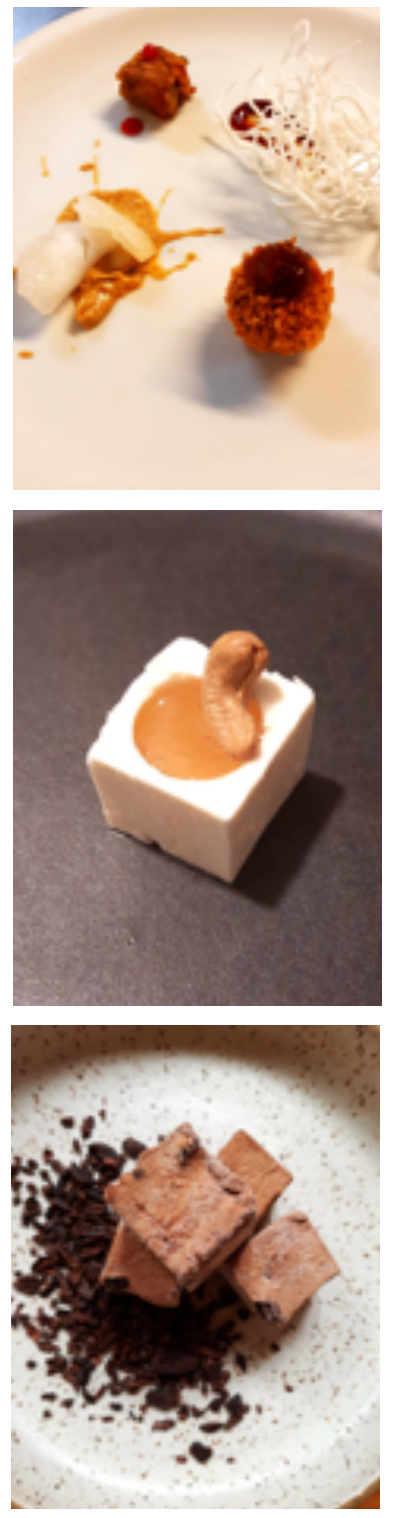

Fig 4. Exemplos de itens do cardápio do projeto VRestaurant Fonte: Projeto VRestaurant, LAE/PUC-Rio, 2021
- Apoio à economia local, relacionamento estreito produtorconsumidor, minimizar o desperdício, transporte

- Fatores econômicos para desperdício de comida, distâncias, falta de consciência, excesso de alimentação $\mathrm{x}$ desnutrição

- Ética: tratar as pessoas com igualdade e respeito, o mesmo para os animais

- Problemas de saúde causados pelo consumo excessivo de alimentos processados

Todas essas questões foram baseadas nas recomendações propostas pelo The Eat Lancet Commision of Food, Planet, Health ${ }^{4}$, órgão não-governamental que reuniu 37 cientistas de 16 países para responder à pergunta: teremos como alimentar 10 bilhões de pessoas com uma dieta saudável, em 2050, dentro dos limites planetários da Terra? Em resposta, os pesquisadores sugerem duas metas - dietas saudáveis e produção sustentável de alimentos - que podem ser atingidas a partir de cinco estratégias: compromisso internacional para firmar dietas saudáveis; reorientar as prioridades agrícolas para produzir alimentos saudáveis; intensificar de forma sustentável a produção de alimentos para aumentar a produção de alta qualidade; governança coordenada da terra e dos oceanos; e reduzir ao menos pela metade o desperdício de alimentos.

Os itens do cardápio (Figura 4), criado exclusivamente para esta experiência, bem como os ingredientes e processos de preparação gastronômicos, foram planejados e produzidos pela Chef Ellen Gonzalez, profissional da área de Gastronomia e também doutoranda em Design da PUC-Rio, de forma a contemplar cada um dos desafios acima descritos, propiciando aos participantes uma experiência imersiva e sinestésica ímpar. Houve ainda uma preocupação com a forma, o tamanho e a consistência dos itens do cardápio, para que - num ambiente de imersão virtual - possam ser manipulados com as mãos (finger food), e sejam fáceis de morder, mastigar e ingerir (bite size).

Nosso objetivo final é promover a conscientização, o engajamento e a mudança de comportamento em questões relacionadas a dietas saudáveis e sistemas alimentares sustentáveis.

Temos ainda, por objetivo, explorar aspectos conceituais e tecnológicos dos novos territórios da Realidade Virtual, Aumentada e Mista, visando investigar o potencial desses recursos para o campo do Design. Com as possibilidades tecnológicas atualmente disponíveis, e com o desenvolvimento de elementos e técnicas que promovam a sensação de presença, a suspensão de descrença, o engajamento e a motivação, esses processos podem ser vividos, incorporados, experimentados, acionados e sentidos pelos próprios participantes da experiência, de forma individual ou colaborativa.

Todos os fatores relacionados ao conforto, à facilidade de uso e à satisfação dos participantes estão sendo observados. A sensação de náusea, tontura e enjoo - que ocorre quando o usuário precisa se locomover pelo mundo virtual - está sendo considerada, e por isso, enquanto estão vestidos com os headsets, os participantes permanecerão sentados. 
Nossa intenção também foi a de conceber um projeto de imersão coletiva, interativa e colaborativa, em Realidade Virtual. Tal como LAYNG et al. (2019), entendemos que compartilhar uma narrativa em um espaço virtual transforma a experiência e a amplia. Sua multimodalidade possibilita pela incluir textos, imagens, animações, som, feedback tátil, e até aromas e paladar - e esta é uma importante característica da tecnologia digital, que permite criar experiências virtuais ainda mais envolventes e multissensoriais, e que vamos explorar de forma pioneira.

Sem duvida, para além dos sentidos mais tradicionalmente usados de audição e visão, também vamos explorar originalmente a potencialidade dos sentidos do paladar, olfato e tato.

A despeito das dificuldades causadas pela pandemia, este ano, o projeto da instalação continua a ser desenvolvido, e está em fase pré-final de desenvolvimento, devendo ser apresentado ao publico ainda este ano.

\section{Considerações Finais}

Mark Weiser, visionário autor de conceitos como computação ubíqua e tecnologias calmas - percebia a Realidade Virtual como sendo "diametralmente oposta" à computação ubíqua (Weiser, 1991. p. 94).

Em seu seminal artigo The Computer for the 21st century, o autor dizia que a Realidade Virtual - ao tentar representar o mundo real dentro do computador - apenas simulava-o parcialmente, deixando de fora não apenas objetos e pessoas não equipadas com headsets e aparatos especiais, mas também o clima, a natureza, os encontros casuais, e outras coisas que considerava ser "a riqueza infinita do universo". Para Weiser, a Realidade Virtual se concentra em apenas simular o mundo, ao invés de aprimorar, de forma invisível, a realidade que já existe.

Essa não é, no entanto, a visão dos artistas e pesquisadores que exploram a potencialidade das novas tecnologias imersivas de Realidade Virtual, e nesse grupo se inclui o Laboratório de Arte Eletrônica da PUC-Rio.

Não nos interessa simplesmente imitar ou simular a realidade, mas examiná-la, compreendê-la, expandi-la, e - principalmente - criticá-la, modificá-la e transformá-la, por meio de recursos digitais inovadores. Quéau (1995) diz que o virtual nos oferece uma outra experiência do real. Nossa visão, contudo, vai mais além: acreditamos que o virtual pode - e deve - nos oferecer um novo, crítico e transformador olhar sobre o real.

Nessa linha, os projetos do Laboratório de Arte Eletrônica têm por meta sensibilizar, engajar e transformar o cidadão, facilitando o entendimento de questões complexas, gerando conhecimento de forma accessível, inteligível, lúdica e interativa, e permitindo a conscientização do público em relação a temas relevantes para o ser humano e o meio ambiente.

A Arte Eletrônica tem um papel essencial como elemento facilitador para a promoção de conscientização, engajamento e mudanças sociais.

o futuro ainda não existe, cabe a nós construí-lo. 
Agradecimentos

Meus sinceros agradecimentos aos professores, alunos e colaboradores que fazem parte da equipe atual do Laboratório de Arte Eletrônica da PUC-Rio - Alexandre Cantini Rezende, Helena Cavalcanti de Albuquerque, Wesley Lopes de Oliveira, Ellen Gonzalez, Bruno Rego, Victhor Kronemberger, Miguel Lessa Carregal, Rafael Costa, Luciana Leme - por sua imensa dedicação, especial talento e inigualável amizade. Meus agradecimentos também à Cecy Rangel, pela locução do vídeo, e aos demais colegas que nos ajudaram, de alguma forma, nesses tempos difíceis de pandemia. Agradeço ainda a Francisco Oliveira de Queiroz e à equipe da School of Design, University of Leeds (Reino Unido), ao Departamento de Artes \& Design da PUC-Rio, e às demais instituições parceiras do LAE, por seu apoio, incentivo e confiança.

10 projeto Sensorama pode ser visto em detalhe neste histórico vídeo, em que seu próprio criador, Morton Heilig, aparece exibindo a câmera customizada para captação em 3-D usada para criar os filmes originais apresentados aos participantes. https://vimeo.com/246184069

2 Documentário sobre a instalação imersiva Osmose, de Char Davies (1995). Disponível em: https://www.youtube.com/watch?v=bsT59fp8LpY 30 vídeo gravado durante o Painel esta disponível em: https://www. youtube.com/watch?v=LZCX0yH9gLM\&t=2145s

4 https://eatforum.org/eat-lancet-commission/eat-lancet-commission-summary-report/ 


\section{Referências}

BAILENSON, J. The Future of Virtual Reality: Experience on Demand. 2018. Disponível em: https://www.youtube.com/watch?v=V5Sk7ox8gYI. Acesso em: 20 de abril de 2019.

BROCKWELL, H. "Forgotten genius: the man who made a working VR machine in 1957". Tech Radar. 3 April 2016. Acesso em: 7 Novembro 2020. Disponível em: https://www.techradar.com/news/wearables/forgotten-genius-the-man-who-made-a-working-vr-machine-in-1957-1318253/2

DAVIES, C. Virtual Space. In: PENZ, F.; RADICK, G.; HOWELL, R. (orgs) Space: In Science, Art and Society. Cambridge University Press, 2004, pp. $69-104$.

EVANS, C. Brenda Laurel's Placeholder: In dreams everybody flies their own way. 01 December 2018. Acesso em 12 dezembro 2020. Disponível em: https://www.artlink.com.au/ articles/4724/brenda-laurelE28099s-placeholder-in-dreams-everybody-fl/

FAUVILLE, G.; QUEIROZ, A.C.M.; BAILENSON, J.N. (2020) Virtual reality as a promising tool to promote climate change awareness. In Kim, J. \& Song, H (Ed.) Technology and Health: Promoting Attitude and Behavior Change (pp. 91-108). Elsevier. doi.org/10.1016/B978-0-12816958-2.00005-8

FILIPPO, D.; RAPOSO, A.; ENDLER, M.; FUKS, H. Ambientes Colaborativos de Realidade Virtual e Aumentada. In: KIRNER, C. AND SISCOUTTO, R. (2007). Realidade Virtual e Aumentada: Conceitos, Projeto e Aplicações. Porto Alegre: Editora SBC.

FRAYLING, C. Research in Art and Design. London: Royal College of Art Research Papers, Volume 1, Number 1, 1993/4.

FREIRE, P. A educação é um ato político. Cadernos de Ciências, Brasilia, n 24, p. 21-22.

GOCHFELD, D.; PERLIN, K.; BRENNER, C.; LAYNG, K., HERSCHER, S.; DEFANTI, C.; GOSPODAREK, M.; SHINN, D.; RIGGS, S.; FERNÁNDEZ-VARA, C. Holojam in Wonderland: immersive mixed reality theater. Leonardo, Vol. 51, No. 4, pp. 362-367, 2018.

GONZALEZ, E. Social innovation possibilities on food production-consumption relationship: an eye on the design of short food supply chains and the local markets, $7^{\circ}$ Simpósio Design Sustentável, Blucher Design Proceedings, Volume 6, 2019, Pages 194-201, ISSN 2318-6968, http://dx.doi.org/10.1016/7dsd-1.2.018

GOTTSCHALK, M. Virtual Reality Is the Most Powerful Medium of Our Time. Artsy.net. Acesso em 15 abril 2019. Disponível em: https://www.artsy.net/article/artsy-editorial-virtual-reality-is-the-most-powerful-artistic-medium-of-our-time

GRAU, O. Virtual Art: From illusion to immersion. Cambridge, Mass: MIT Press, 2003.

KOETSIER, J. VR Needs More Social: 77\% of Virtual Reality Users Want More Social Engagement, Forbes, 30 April 2018. Disponível em: https://www.forbes.com/sites/johnkoetsier/2018/04/30/virtual-reality-77-of-vr-users-want-more-social-engagement-67-use-weekly-28-use-daily/?sh=52f35a0418fc Acesso em: 20 dezembro 2020.

LAYNG, K.; PERLIN, K.; HERSCHER, S.; BRENNER, C.; MEDURI, T. CAVE: Making Collective Virtual Narrative. Leonardo, Vol. 52, No. 4, pp. 349-356, 2019

LAUREL, B. What Is Virtual Reality? Medium. 2016. Disponível em: https://medium.com/@ blaurel/what-is-virtual-reality-77b876d829ba\#.gongffe8h. Acesso em 22 abril 2019.

MACHON, J. Immersive Theatres: Intimacy and Immediacy in Contemporary Performance. New York: Palgrave Macmillan, 2013. 
NASCIMENTO, B.E.M.; GAMBA Jr., N.; OLIVEIRA, L.; PEREIRA, M. G.; SPITZ, R.; GLEISER, S.; PEREZ, C.; VIANNA, C.; CAVALCANTE, T.; VOLCHAN, E. Neurociências, artes gráficas e saúde pública: as novas advertências sanitárias para maços de cigarros. Hist. cienc. Saúde - Manguinhos [online]. 2010, vol.17, suppl.1 p. 243-252. Disponível em: http://dx.doi.org/10.1590/ S0104-59702010000500014. Acesso em: 10 maio 2019.

OLIVEIRA, W. L. de. Estudo sobre presença em ambientes de Realidade Virtual e Realidade Mista com interfaces hápticas. 2019. Dissertação (Mestrado em Computação) - Instituto de Computação, Universidade Federal Fluminense, Niterói, RJ.

PAUL, M.; BULLOCK K.; ARNOW B.; BAILENSONJ.N. Case Report: Virtual Reality Behavioral Activation as an Intervention for Major Depressive Disorder.JMIR, 2020. doi.org/10.2196/24331 QUÉAU, P. Lo virtual: virtudes y vértigos. Barcelona: Paidós, 1995.

REGALADO, N. Planeta joga no lixo 1,3 bilhão de toneladas de comida ao ano. Quanto você desperdiça? Gazeta de São Paulo, 5 setembro 2020. Disponível em: https://www.gazetasp.com. br/colunistas/nilson-regalado/2020/09/1075420-planeta-joga-no-lixo-1-3-bilhao-de-toneladas-de-comida-ao-ano--quanto-voce-desperdica.html Acesso em: 2 janeiro 2021.

SPITZ, R. (ed.) Desorientação e colaboração no cotidiano digital. Rio de Janeiro: Rio Books, 2014, 284p.

SPITZ, R. Qualitative, Dialectical and Experiential Domains of Electronic Art. Leonardo, 28(4), 319-323. 1995. doi:10.2307/1576197

SPITZ, R. Netizens, Net-fringers and Outsiders. In: ACM SIGGRAPH 2001. Electronic Art and Animation Catalog - Computer Graphics Annual Conference Series, ACM SIGGRAPH, 2001. New York: ACM SIGGRAPH, 2001. p.133.

SPITZ, R. Intimate Science for the Naked Eye. In: DOMSCHKE, G., FERRAN, B., MAHFUZ, R.; WOLFSBERGER, A. (eds). Paralelo - Unfolding Narratives: in Art, Technology \& Environment / Paralelo - Narrativas em Percurso: sobre Arte, Tecnologia e Meio-Ambiente. British Council, AHRC (Arts \& Humanities Research Council) \& Mondriaan Foundation, Virtueel Platform, 2010. p. 216 -225 SPITZ, R. De quoi avez-vous faim? (Você tem fome de que?). In: Anomalie digital_arts \#5. (Org.). ://brasil - Festival Art Outsiders 2005. 01 ed. Orleans: Editions HYX, 2005. v. 01, p. 236-249.

SPITZ, R. O que um designer estará projetando em 2065? Inquietações e contribuições do Laboratório de Arte Eletrônica. Estudos em Design. v. 28, n. 2 (2020), pp. 99 - 111.

SPITZ, R; GAMBA Jr., N. Design \& campanhas anti-tabagismo: as novas imagens e advertências a serem impressas nos maços de cigarro no Brasil. In: CONGRESSO INTERNACIONAL DE DESIGN DA INFORMAÇÃO, 3. Anais do 3ํㅡㄹ Congresso Internacional de Design da Informação. Curitiba: 2007. s/n.

SPITZ, R. PEREIRA Jr., C.; QUEIROZ, F.; LEITE, L. C.; DAM, P.; REZENDE, A. C. Gamification, citizen science and civic technologies: in search of the common good. Strategic Design Research Journal, 11(3): 263-273, September-December 2018, Unisinos. Disponível em: http://revistas. unisinos.br/index.php/sdrj/article/view/sdrj.2018.113.11 Acesso em: 11 agosto 2020.

SUTHERLAND, I. E. The Ultimate Display. Proceedings of IFIP Congress, 1965, pp. 506-508, 1965. Disponível em: https://www.wired.com/2009/09/augmented-reality-theultimate--display-by-ivan-sutherland-1965/ Acesso em: 21 outubro 2019.

SUTHERLAND, I. E. A head-mounted three dimensional display. 1968, Disponível em: http://cacs.usc.edu/education/cs653/Sutherland-HeadmountedDisplay-AFIPS68.pdf Acesso em: 10 janeiro 2021.

Recebido: 19 de novembro de 2020. Aprovado: 25 de novembro de 2020.
WEISER, M., The computer for the 21st century., in Scientific American, 265(3):66-75, January 1991. 